\title{
NUMERICAL OPTIMIZATION OF SANDWICH COMPOSITE STRUCTURE UNDER FLEXURAL LOAD
}

\author{
Essam Zuheir Fadhel \\ essam_zuher@yahoo.com
}

University of Babylon / College of Engineering Mechanical Engineering Department

\begin{abstract}
The structures of a sandwich composite have been utilized in the aerospace industry and engineering applications. Prediction of a theoretical composite construction's flexural properties is important for efficient composite products design. In this investigation, four different core shapes were used in the fabrication of the sandwich frames with constant volume of sandwich composite structure in each case; these are hexagonal, rectangular, triangular and circular. The effect of core stiffeners number was studied to finding the best stiffeners number which gives the highest properties in strength using the finite element analysis.

The material of the each face sheet is consisting from epoxy with four layers of a woven fiberglass laminate construction, and the core stiffener material consists from epoxy matrix with carbon fiber, the fiber volume fraction was $60 \%$ for both skins and core composites.

The analysis of the three point bending load with a value of $(10 \mathrm{kN})$ conducted by constructing a finite element model, explained that the best shape of core was rectangular which give less deflection value of $(11.939 \mathrm{~mm})$ from the other shapes, for the same properties of material and constant core volume in each case. Also, it was determined the optimum stiffeners number, for the rectangular core, was five stiffeners in longitudinal direction and twelve stiffeners in transverse direction, gives strengthen structure.
\end{abstract}

KEYWORDS: Honeycomb, sandwich panel, composite material, flexural load.

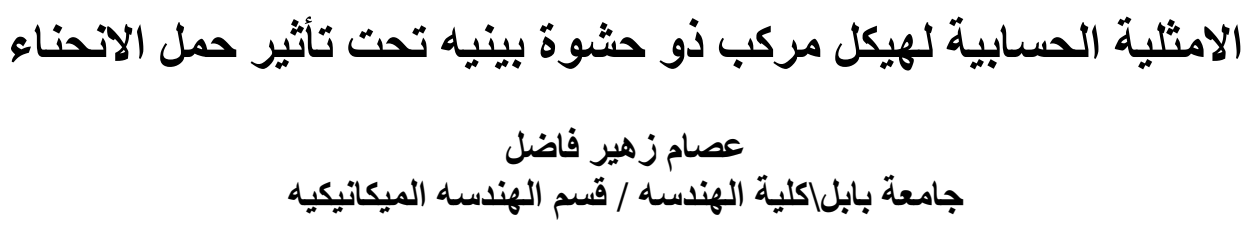

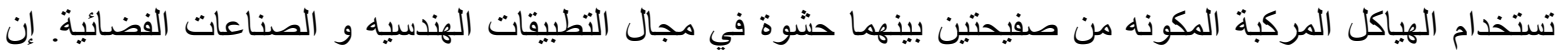

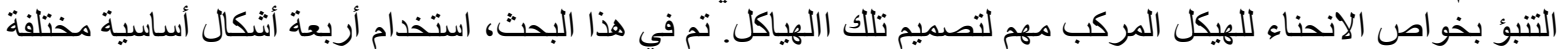

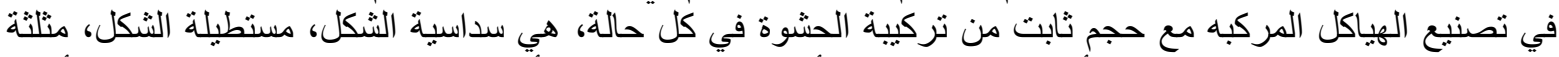

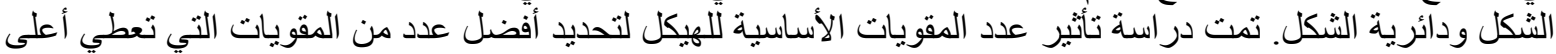

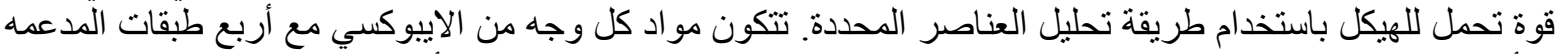

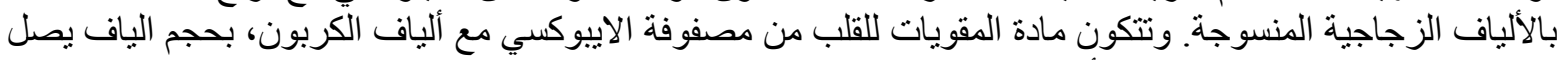

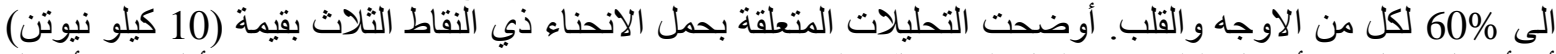

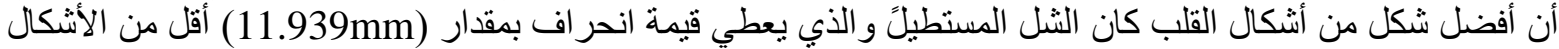

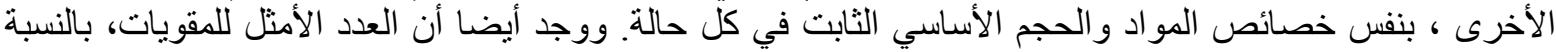
للنواة المستطيلة (الذي يعطي اقوى بنيه للهيكل)، كان خمسة مقويات في الاتجاه الطولي واثني عشر تقوية في الاتجاه

الكلمات المفتاحيه: خلية النحل، لوحة الساندويش، المادة المركبه، حمل الانحناء. 


\section{INTRODUCTION}

The sandwich panels are used for increasing the performance with light weight structures. Sandwich panels consist of two stiff and thin skins and thick and lightweight core bonded between them. The face sheets support flexural stiffness and core transmit shear between skins. Also, the flexural stiffness contributes to a strong core. Cores are made of foams or they are fabricated using truss, corrugated or honeycomb structures, Satay and Nirmala [2016].

The aerospace industry uses sandwich structured composites as a cheap method to increasing the flexural strength of fiber reinforced composites. The core of the sandwich panel doesn't support the load therefore it doesn't need to be strong, so the material usually used is inexpensive, Jabihulla and Sudhir [2016].

In a sandwich structure, due to the layout of the material the bending loads are supported by the force couple formed by the face sheets, and the shear loads are supported by the core material. The face sheets are strong and stiff in tension and compression as compared to the low weight core material whose main purpose is to keep the face sheets at a space in order to serve a high modulus of the section (a high moment of inertia). Therefore, sandwich panels are highly active in carrying bending loads, Sezgin et al. [2010].

Therefore, composite sandwich structures is used in most engineering application for example; marine, mechanical structures, aeronautical, civil engineering applications is wider because these structures have more desirable properties and excellent stiffness to weight ratios that leads to weight reduction and decreasing the fuel consumption, Mamalis et al. [2005].

Zakeri and Talebi [2010] studied the mechanical behavior of sandwich panels for dynamic loads experimentally. For this investigation, flexural test under different conditions of load was affected strongly by skin thickness, but tensile and compression properties of a sandwich panel depended on material of core.

Kiumars et al. [2015] focused on the dynamic response of honeycomb sandwich panels with square cell shape made from super austenitic stainless steel alloy using numerical analysis. Different loads with impulse type were applied on the sandwich structures. It was found that, the honeycomb sandwich bodies suffered significantly from smaller back face deflections than identical mass solid plates.

While Sakhi et al. [2015] investigated the three points bend flexure behavior of the honeycomb sandwich panels experimentally and analytically. Composite of fiber glass skins with aluminum honeycomb core were utilized for the manufacture of the test specimens. It concluded that the maximum breaking load with the maximum deflection, while the failure of the specimens occurred due to buckling of the core and the buckling causes the dispersing of the face sheet from the core.

Nitin et al. [2016] included the flexural strength of composite panel made of eight layers of fiber glass sheets arranged with various degree of orientation. Increasing loads were applied gradually to examine the honeycomb sandwich behavior composites through three point bending stress. The results were determined experimentally and by using the finite element analysis. It obtained that, the flexural strength of aluminum honeycomb panel with composite layup was twice of that the aluminum honeycomb panel flexural strength.

Satay and Nirmala [2016] described a honeycomb sandwich structure made of a jute fiber with epoxy resin reinforced. The characteristics of the response under three point bending were determined experimentally and by using finite element method. The results concluded that, the fiber of jute reinforced circular core structure had greater flexural strength as compared to cores of hexagonal fiber of jute reinforced.

The aim of the present study is to investigate the optimum shape of sandwich panel core (rectangular, hexagonal, triangular and circular) under three point bending load. The flexural strength characteristics of honeycomb sandwich panels made of epoxy-fiber glass face four layers sheet with $\left(0^{\circ}, 45^{\circ},-45^{\circ}\right.$ and $\left.90^{\circ}\right)$ directions and epoxy-carbon fiber core, with the 
volume fraction of fiber as $(60 \%)$ for both materials, was determined. In the present work, the optimum number of stiffeners for core's structure has been studied numerically, that give strengthen structure. It can be determined these parameters effect by using the finite element analysis (FEA).

\section{Material and Geometric Parameters}

A sandwich panel structure is a special shape of laminated composites, where this structure consists of two thin face sheets have high strength and bonded to a light weight and thick core as shown in figure (1). The core is flexible and weak and the face sheet skins relatively are rigid, however when combined in a sandwich structure they produce a structure that is strong, stiff and lightweight, where many aerospace structures are made of quasi isotropic composite materials, Rocca and Nanni [2005].

The plies of a face sheets quasi isotropic layer are stacked in sequence is $\left[0^{\circ}, 45^{\circ},-45^{\circ}\right.$, and $90^{\circ}$ ]. Each ply consists of glass/epoxy with fiber volume fraction of $60 \%$. Table (1) shows the dimension of structure plate used in this study.

The properties (Young's modulus, Shear modulus, Poisson's ratio and Density) of the composite materials are determined theoretically using mixture rule as following, George S. Springer [2003]

$$
\begin{aligned}
& \mathrm{E}_{1}=\mathrm{E}_{\mathrm{f}} \mathrm{V}_{\mathrm{f}}+\mathrm{E}_{\mathrm{m}} \mathrm{V}_{\mathrm{m}} \\
& \mathrm{E}_{2}=\frac{\mathrm{E}_{\mathrm{f}} \mathrm{E}_{\mathrm{m}}}{\mathrm{E}_{\mathrm{f}}+\mathrm{V}_{\mathrm{f}}\left(\mathrm{E}_{\mathrm{f}}-\mathrm{E}_{\mathrm{m}}\right)} \\
& \mathrm{G}_{12}=\frac{\mathrm{G}_{\mathrm{f}} \mathrm{G}_{\mathrm{m}}}{\mathrm{G}_{\mathrm{f}}-\mathrm{V}_{\mathrm{f}}\left(\mathrm{G}_{\mathrm{f}}-\mathrm{G}_{\mathrm{m}}\right)} \\
& \mathrm{G}_{23}=\frac{\mathrm{E}_{\mathrm{z}}}{2\left(1+v_{\mathrm{gs}}\right)} \\
& \mathrm{v}_{12}=v_{\mathrm{f}} \mathrm{V}_{\mathrm{f}}+\mathrm{v}_{\mathrm{m}} \mathrm{V}_{\mathrm{m}} \\
& \mathrm{v}_{23}=\frac{\mathrm{E}_{2}}{2 \mathrm{G}_{2 \mathrm{~s}}}-1 \\
& \rho=\rho_{\mathrm{f}} \mathrm{V}_{\mathrm{f}}+\rho_{\mathrm{m}} \mathrm{V}_{\mathrm{m}}
\end{aligned}
$$

Where:

$\mathrm{E}_{1}, \mathrm{E}_{2}$ : major and minor modulus of elasticity respectively (GPa).

$E_{f}$ : modulus of elasticity of fiber (GPa).

$\mathrm{E}_{\mathrm{m}}$ : modulus of elasticity of matrix $(\mathrm{GPa})$.

$\mathrm{V}_{\mathrm{f}}$ : fiber volume fraction.

$\mathrm{V}_{\mathrm{m}}$ : matrix volume fraction.

$\mathrm{G}_{12}, \mathrm{G}_{23}$ : major and minor shear modulus respectively (GPa).

$\mathrm{G}_{\mathrm{f}}$ : shear modulus of fiber.

$\mathrm{G}_{\mathrm{m}}$ : shear modulus of matrix.

$v_{12}, v_{23}$ : major and minor Poisson's ratio respectively.

$v_{\mathrm{f}}$ : Poisson's ratio of fiber.

$v_{\mathrm{m}}$ : Poisson's ratio of matrix.

$\rho$ : density of composite $\left(\mathrm{g} / \mathrm{cm}^{3}\right)$.

$\rho_{\mathrm{f}}$ : fiber density $\left(\mathrm{g} / \mathrm{cm}^{3}\right)$.

$\rho_{\mathrm{m}}$ : matrix density $\left(\mathrm{g} / \mathrm{cm}^{3}\right)$.

The properties of the composite materials used in this study illustrated in table (2). These properties were calculated for the core with carbon fiber - epoxy material using equations (1-7), 
while for fiber glass-epoxy material of skins was determined in this table by using the Laminator program (Version 3.7).

In order to get best comparison between the suggested geometrical core shapes of the system, the present study regarded the weight criterion to be constant (i.e. the core volume is fixed). Also where taking the sample with constant volume faction for each core shape with $(60 \%)$ of carbon fiber. By this procedure it can be determined the cell shape which has the larger strength to support the same three point bending load of $(10 \mathrm{kN})$ in each case. In this study, it can be used different shapes of core to determine the strengthen shape; these are hexagonal, rectangular, triangular and circular as shown in figure (2).

\section{Finite Element Analysis}

The finite element technique is used to analyze the sandwich structure composite. A finite element model with three dimension analysis used to describe the materials principal direction stresses and deformations distribution in the honey comb sandwich structure by using Ansys Workbench 16. The sandwich body is composed of a carbon fiber epoxy core composite with two skins made from a fiber glass epoxy composite.

In addition, it carried out bending load on honeycomb structural composite material having differing shapes and sizes of cells where the volume of the core is constant, and then observed the honeycomb structural deformity characteristics.

The two skins and core are glued together as a whole volume. The bonding between the skins and grid core is assumed perfectly. The symmetric constraints are applied on the structure.

The supports of structure designed as solid bodies and sandwich panels faces were assumed to be glued to the rigid supports. Figure (3) demonstrates the model of finite element with meshed honeycomb structure.

\section{Flexural Behavior of Sandwich Panel}

The bending loads in a sandwich structure are supported by the force couple formed by the face sheets and the shear loads are carried by the lightweight core material. The sandwich panel composite under bending can fail in multiple ways. Failure with different modes can occur during testing based on the components of the sandwich panel, and geometry of the panel. The flexural strength of a sandwich panel can be predicted, the most prominent failure mechanism must be known, as it will determine the mechanical details behind the prediction. In several cases, core properties or the interaction between the core and face sheets may need to be characterized to make an accurate prediction of the flexural strength, Nguyen et al. [2005].

The three-point bend load is used in the present study, there are two supports holding the sandwich structures and one load point in the center of the sandwich structures, and the maximum stress is located immediately under the loading nose as shown in Fig. (4), the load will be constant value of $(10 \mathrm{kN})$ in all cases to determine the optimum honey comb sandwich structure.

\section{RESULTS AND DISCUSSIONS}

In this investigation, the volume of wall is constant to provide optimum design in this sandwich panel, and three-point bending load was applied to the sandwich structures in order to evaluate the bending properties of sandwich variation in accordance with the core shape variation and the number of core stiffeners variation.

The study of honeycomb properties is important to determine the range of application of these materials. It may be taken multi type of core shape of cell for the core of honeycomb. To make this comparison between these shapes more accurate, the structure of honeycomb plate should be with the same material properties and volume fraction in each face sheets and core of plate, 
also the applied load is the same of $(10 \mathrm{kN})$ for all cases. In this study, the variables are only the cell wall thickness and number of cell (core shape) to give the constant total volume of core in each case.

It can be observed from figures (5) to (8) that the structure with rectangular cell is less deformation; i.e. stiffer structure; from other cases of core shapes, such as hexagonal, triangular and circular shapes, these details can be shown in table (3). This result because of the stiffeners is more compact in rectangular core, and these stiffeners are building up with each other in both transvers and longitudinal directions.

Also, it can be seen that bending distortion at the peak value decreased for the rectangular core. Also, it can be noticed from these figures that panel bending stiffness at maximum value from the other selected core shapes. Furthermore it is also known that the rectangular core has a higher bending strength when compared to the other core shapes.

The circular, triangular and hexagonal cores have higher deformations under the bending loading, demonstrating that these cores reached yielding strength before rectangular core.

Bending strength of the sandwich panel is one of the most important characteristics, where this strength will depend on the energy absorbing capability of the entire structure. Therefore, the yield strength of the structure material as well as geometrical dimensions such as cell size and wall thickness is the main parameters to determine the bending strength. Where the top skin suffers from the compression stress and the bottom skin bears tension stress during the bending load process.

To determine the percentage difference of the structure deformation by using the following relation:

Percentage difference $=\frac{\text { cell deformation-rectangular cell deformation }}{\text { cell deformation }} * 100$

Table (3) shows the percentage increasing in deformation for the hexagonal, triangular and circular core shapes from deformation of the rectangular core shape structure. And this clear that the hexagonal has minimum percentage increasing in deformation compared with rectangular, while the circular core shape has maximum percentage increasing and gives weaker structure.

The most important property of the core is its ability to bonding with the face sheets to transfer the loads between the top and bottom face sheets. A honeycomb core sandwich panel is lighter due to having the core of hollow space; therefore it must choice a suitable stiffeners distribution to support a higher load with smaller deformation. While in this work, it is very clear the rectangular shape has small deformation for this test (bending load), this because the longitudinal stiffeners play important role to avoid the bending in structure where this property not exist in other shape.

Additionally, to finding the optimum number of stiffeners in longitudinal and transverse directions, it can take the rectangular core shape, which its optimum core shape to support the load with smaller deflection. This number of stiffeners will take with the same total wall thickness to maintain the volume to be constant. In the other word, if the total wall thickness is (4 mm) for longitudinal stiffeners, this thickness must divided on the number of stiffeners which taken to determine the wall thickness with the same total volume of core in each case. In the same procedure it can take the number of stiffeners in the transverse direction. So that, to obtain the constant total wall thickness of the core in each direction, the increasing the number of stiffeners in any direction refers to decrease the wall thickness for each stiffener. By this way it can be insure the overall volume of the core is constant.

From above, it is can choice a number of stiffeners in longitudinal and transverse directions arbitrary as shown in figure (9). In each case the total wall cell thickness in longitudinal direction not exceed $(4 \mathrm{~mm})$ and in transverse direction must not exceed $(10 \mathrm{~mm})$, to stay the 
volume of core and volume fraction of composite to be constant. Noted that, the applied load is $(10 \mathrm{kN})$ in each case to make logical comparison.

The bending behavior for all cases can show in figures (10) to (14). In these figures it can observe that the deformation at point of loading decrease with increase the number of stiffeners, this meaning the strength of structure will increase the number of stiffeners, until reach to five stiffeners in longitudinal and twelve stiffeners in transverse direction as shown in figure (13). After that, the increasing for the number of stiffeners causes increase of the deformation in the mid span of plate, this because the wall thickness of stiffener will be thinner and this thickness cannot support the applied load.

Therefore the bending stresses in the composite structure will increase with increase the number of stiffeners while the core volume will remain constant.

It was indicated that there is an important relation between numbers of core stiffeners increases and bending stresses values as expected. This because that, the supported load distribution is increased with increased the number of stiffeners. This behavior can be shown in table (4). Also the deformation results for each case can be clearly display in figure (15).

The principal stress (Von-Mises stress) is obviously located at the loading region from the top skin, and this stress is less value for number of stiffeners of core is five in longitudinal and twelve in transverse directions as shown in table (4).

\section{CONCLUSIONS}

For this work, it can be concluded that:

1. From the comparison of various core shape structures, it obtained that the rectangular grid cell structure is much stiffer than the traditional honeycomb hexagonal, triangular and circular structures, with three point bending load.

2. The rectangular core structure gave less deflection value of $(11.939 \mathrm{~mm})$ from the other core shapes.

3. The optimum number of stiffeners for rectangular core shape was five stiffeners in longitudinal direction and twelve stiffeners in transverse direction, which gave less deformation and higher strength structure for this case.

Table (1) Plate dimensions use in this work.

\begin{tabular}{|l|l|}
\hline Width $(\mathrm{b})$ & $50 \mathrm{~mm}$ \\
\hline Length $(\mathrm{a})$ & $150 \mathrm{~mm}$ \\
\hline Top face sheet thickness $\left(\mathrm{t}_{\mathrm{f}}\right)$ & $1 \mathrm{~mm}$ \\
\hline Core height $\left(\mathrm{h}_{\mathrm{c}}\right)$ & $3 \mathrm{~mm}$ \\
\hline Bottom face sheet thickness $\left(\mathrm{t}_{\mathrm{f}}\right)$ & $1 \mathrm{~mm}$ \\
\hline Span Length (distance between supports) & $100 \mathrm{~mm}$ \\
\hline
\end{tabular}

Table (2): Mechanical properties of composite materials used in this study.

\begin{tabular}{|c|c|c|c|c|c|c|c|c|}
\hline Material & Vf & E1 (GPa) & E2 (GPa) & G12 (GPa) & G23 (GPa) & $\mathbf{v 1 2}$ & $\mathbf{v 2 3}$ & $\boldsymbol{\rho}\left(\mathbf{g} / \mathbf{c m}^{\mathbf{3}}\right)$ \\
\hline Carbon / Epoxy & $60 \%$ & 181 & 10.28 & 7.172 & 5 & 0.28 & 0.016 & 1.308 \\
\hline Glass / Epoxy & $60 \%$ & 14 & 7 & 7 & 5.333 & 0.312 & 0.312 & 1.98 \\
\hline
\end{tabular}


Table (3): Deformation percentage difference of mid span honeycomb structure with different core shape.

\begin{tabular}{|c|c|c|}
\hline Structural core shape & Max. Deformation $(\mathrm{mm})$ & Percentage difference\% \\
\hline Rectangular & 11.939 & ------ \\
\hline Hexagonal & 14.139 & 15.56 \\
\hline Triangular & 16.575 & 27.97 \\
\hline Circular & 20.088 & 40.56 \\
\hline
\end{tabular}

Table (4): Deformation and stress of the structure with different number of stiffeners.

\begin{tabular}{|c|c|c|c|c|}
\hline \multirow{2}{*}{ No. } & \multicolumn{2}{|c|}{ Number of stiffeners } & \multirow{2}{*}{$\begin{array}{c}\text { Max. deformation } \\
(\mathrm{mm})\end{array}$} & $\begin{array}{c}\text { Von - Mises stress } \\
\text { (MPa) }\end{array}$ \\
\cline { 2 - 3 } & Longitudinal & Transverse & 13.011 & 6432 \\
\hline 1 & 2 & 6 & 12.35 & 5616.7 \\
\hline 2 & 3 & 8 & 11.939 & 4982.2 \\
\hline 3 & 4 & 10 & 11.473 & 4727.9 \\
\hline 4 & 5 & 12 & 12.169 & 5074.8 \\
\hline 5 & 6 & 14 & & \\
\hline
\end{tabular}

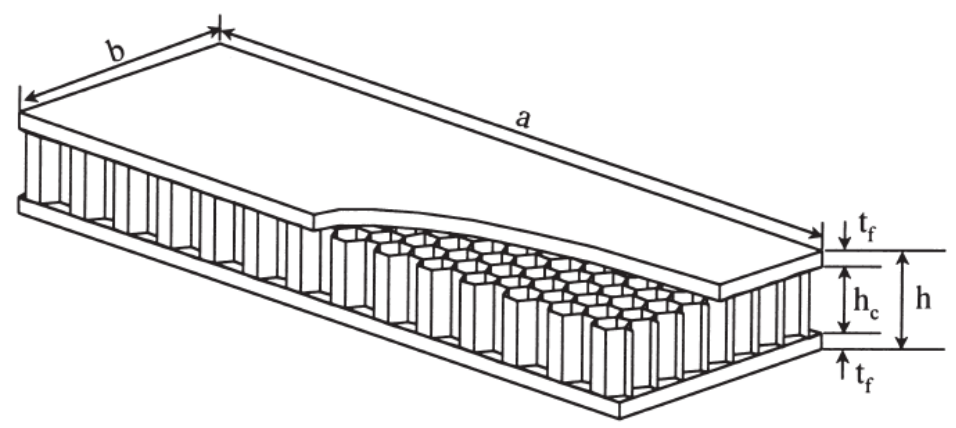

Fig. (1) Sandwich structure components, Jeom et. al [1999].
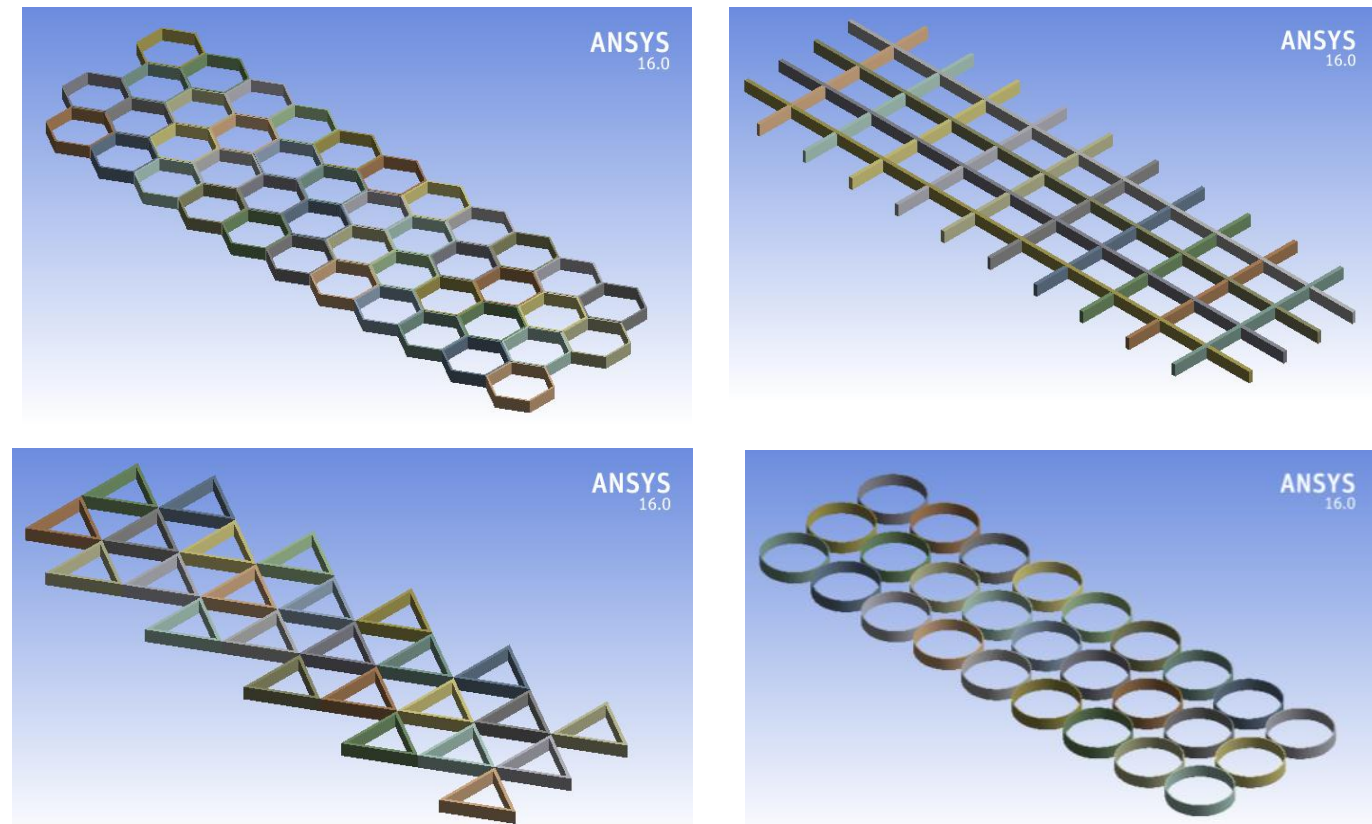

Fig. (2) Cell shapes of the core used in this comparison. 


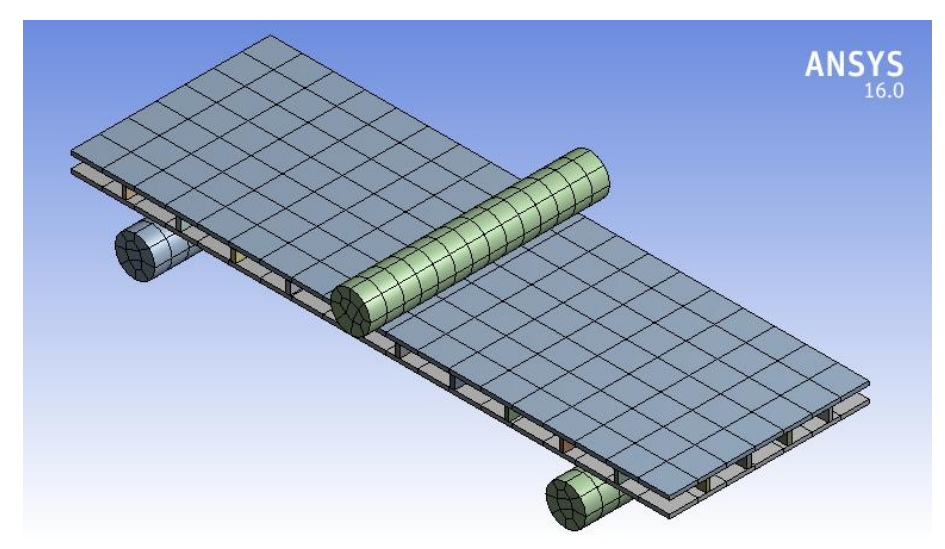

Fig. (3) Meshed honeycomb structure.

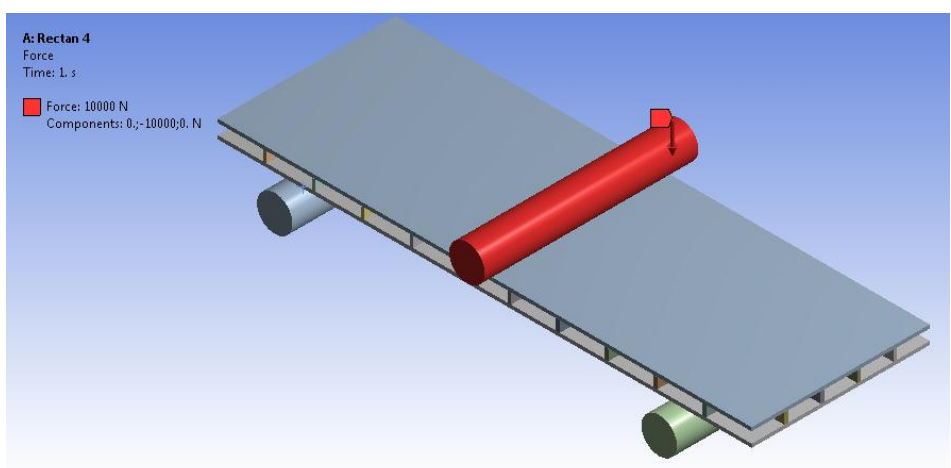

Fig. (4). Finite Element model with bending load.
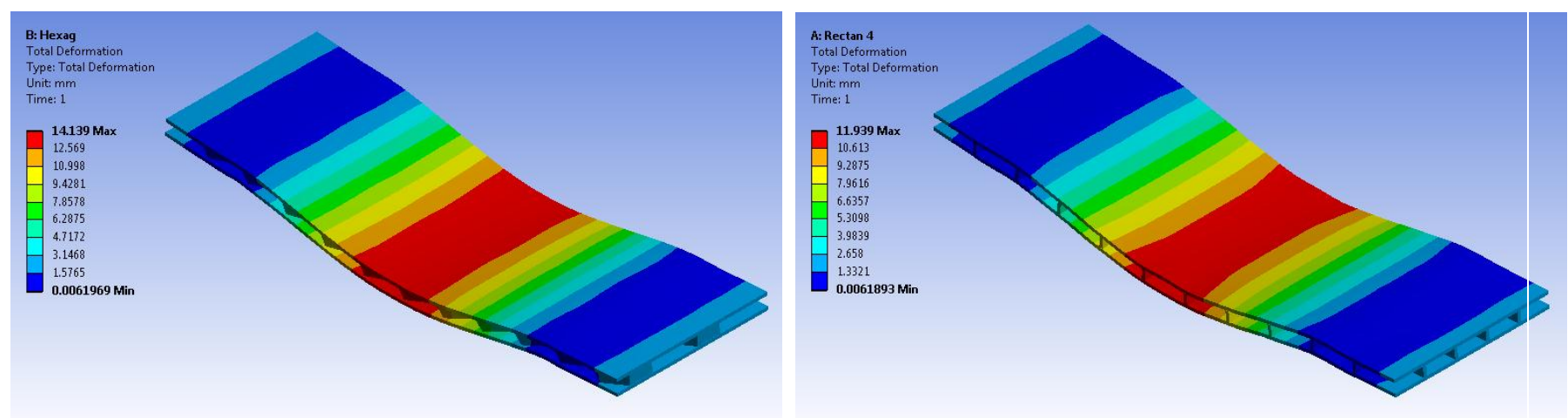

Fig. (5) Deformation structure for hexagonal core. Fig. (6) Deformation structure for Rectangular core. 

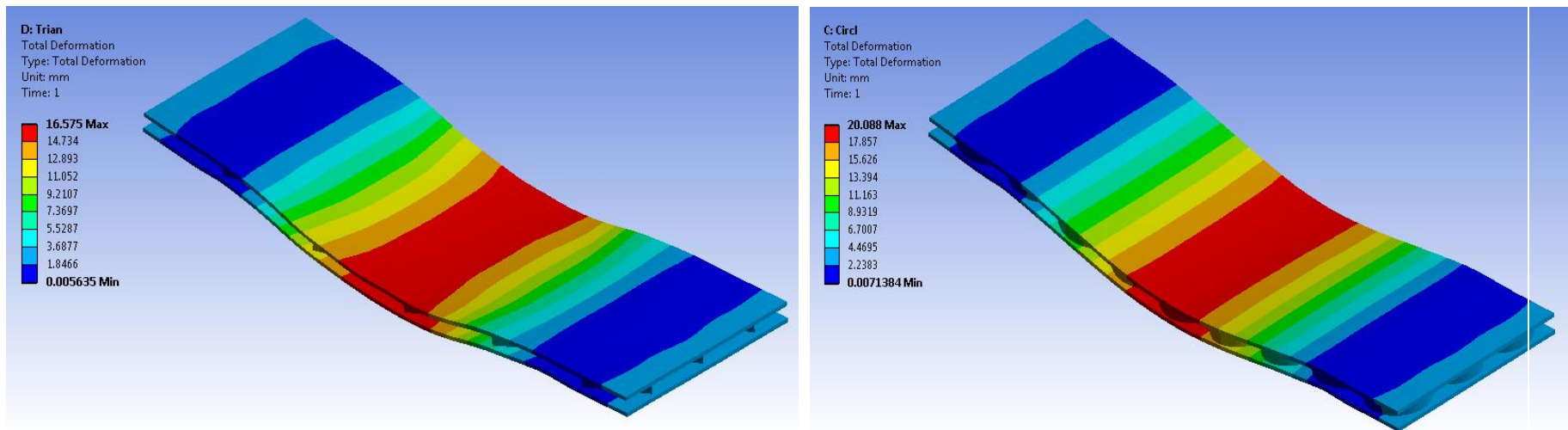

Fig. (7) Deformation structure for Triangular core. Fig. (8) Deformation structure for circular core.
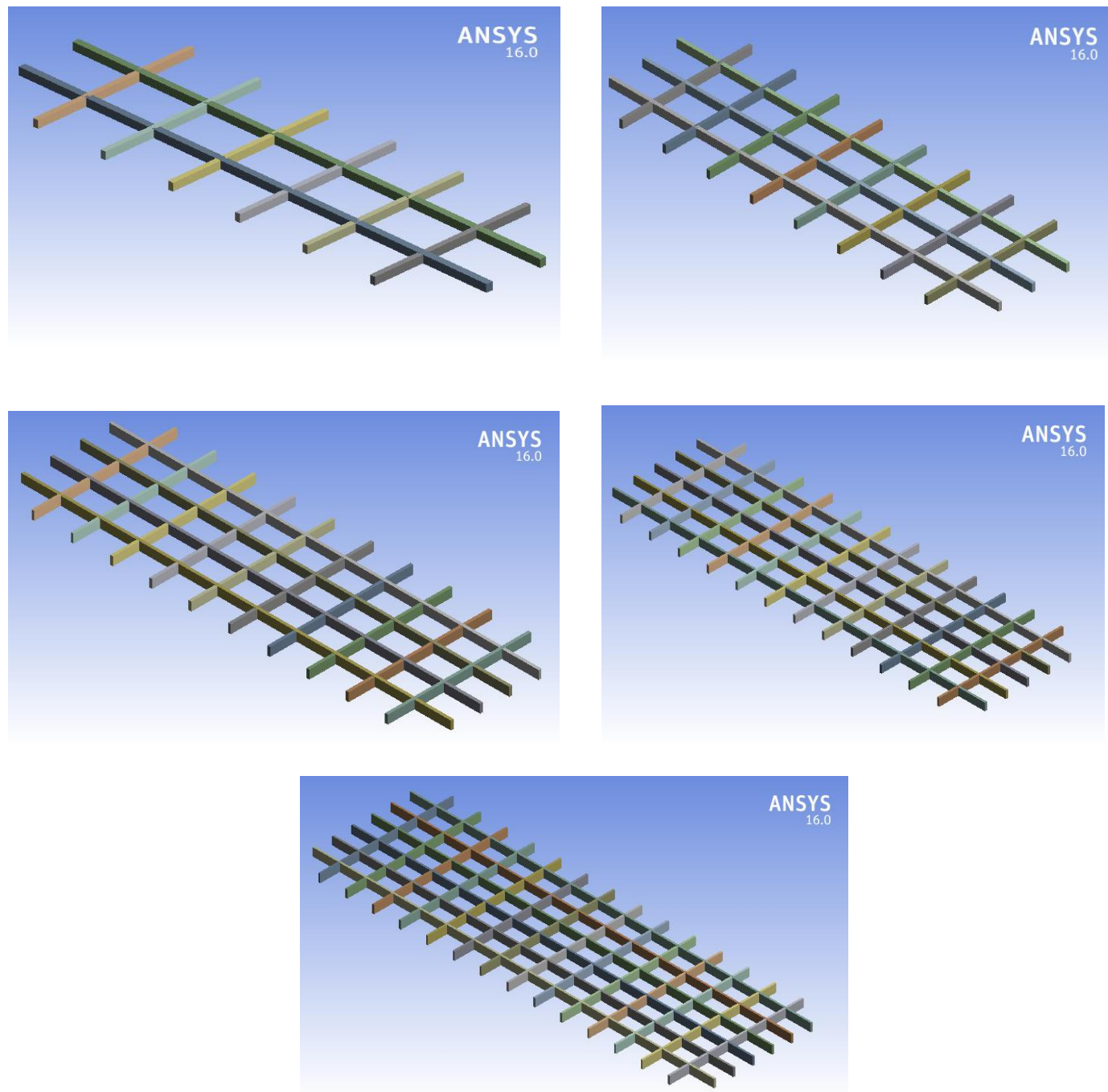

Fig. (9) Number of stiffeners in longitudinal and transvers directions. 

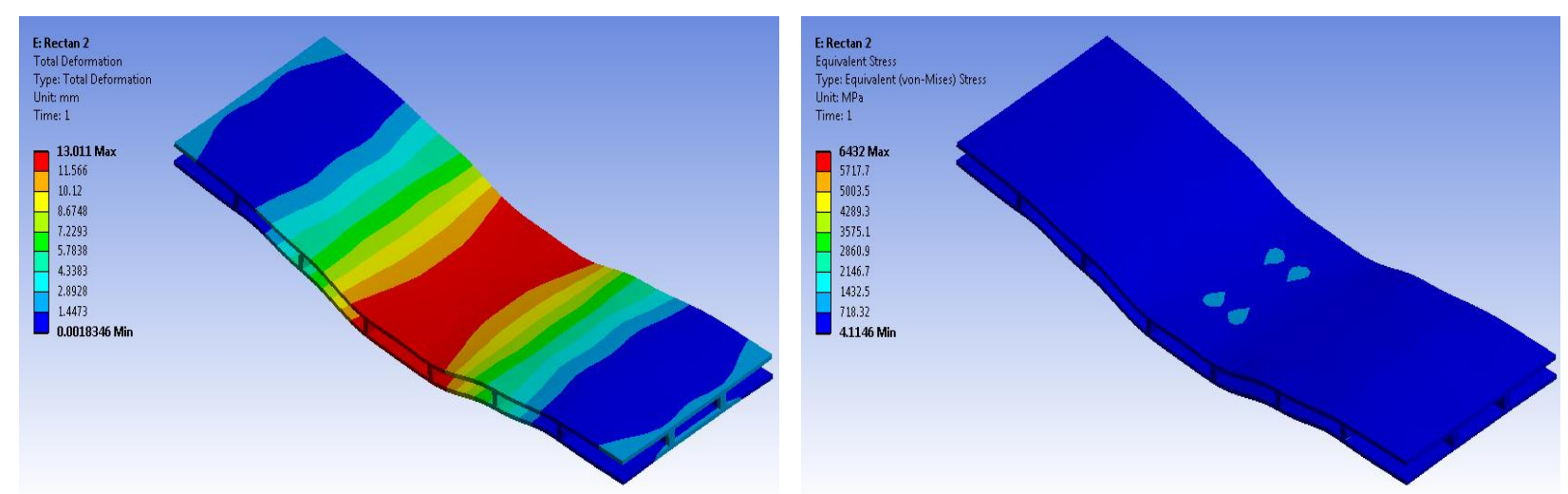

Fig. (10) Deformation and stress of structure with two stiffeners in longitudinal direction and six stiffeners in transverse direction.
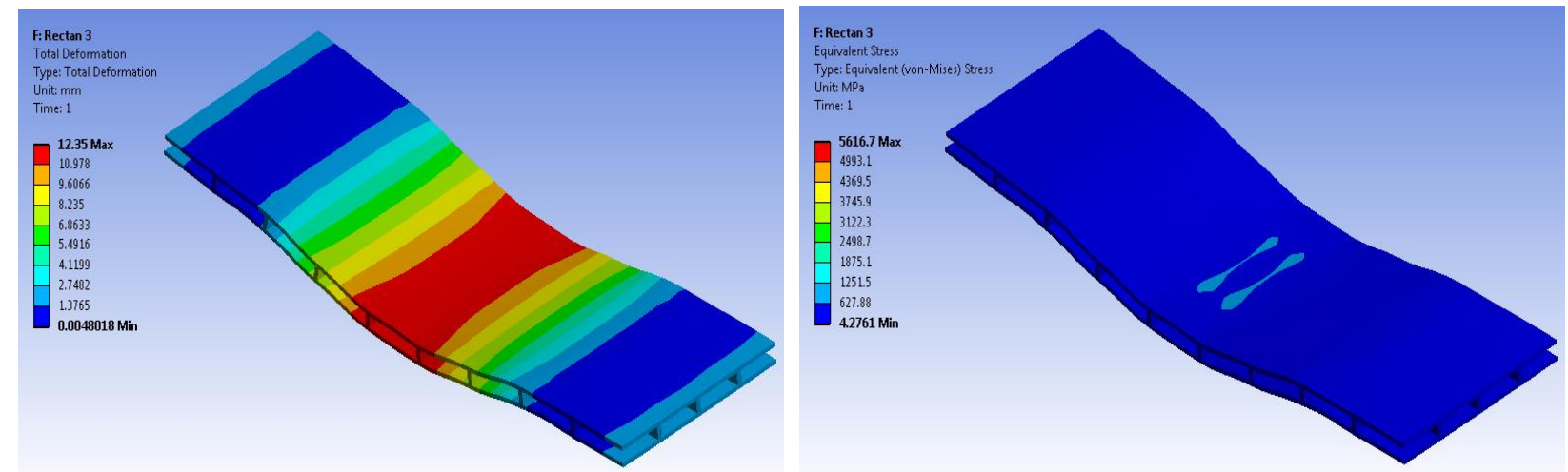

Fig. (11) Deformation and stress of structure with three stiffeners in longitudinal direction and eight stiffeners in transverse direction.
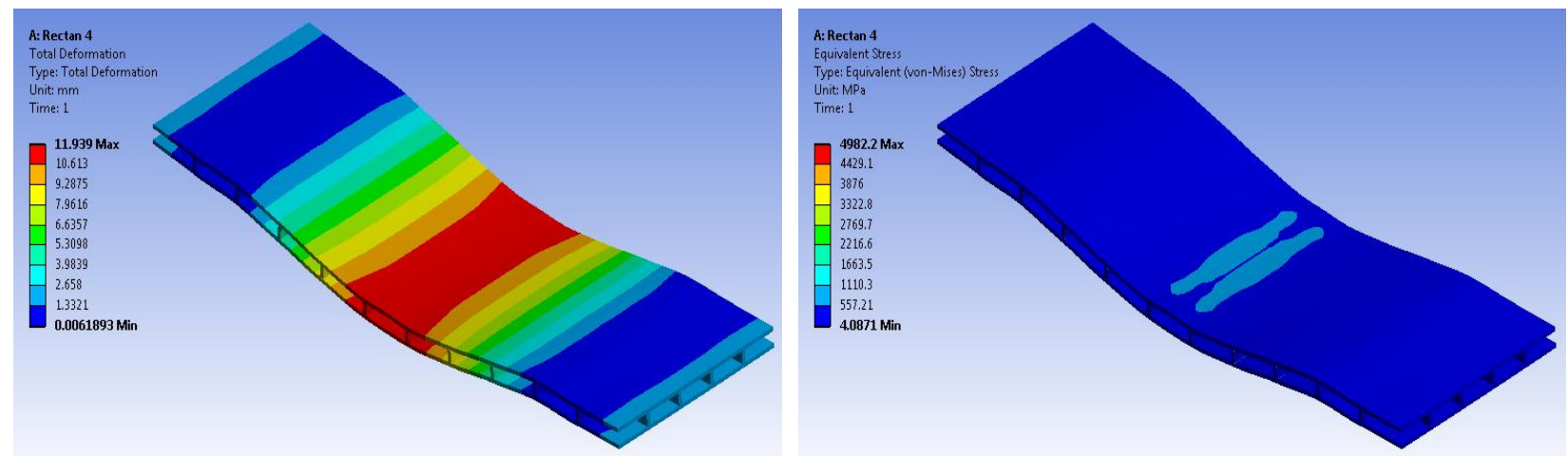

Fig. (12) Deformation and stress of structure with four stiffeners in longitudinal direction and ten stiffeners in transverse direction. 


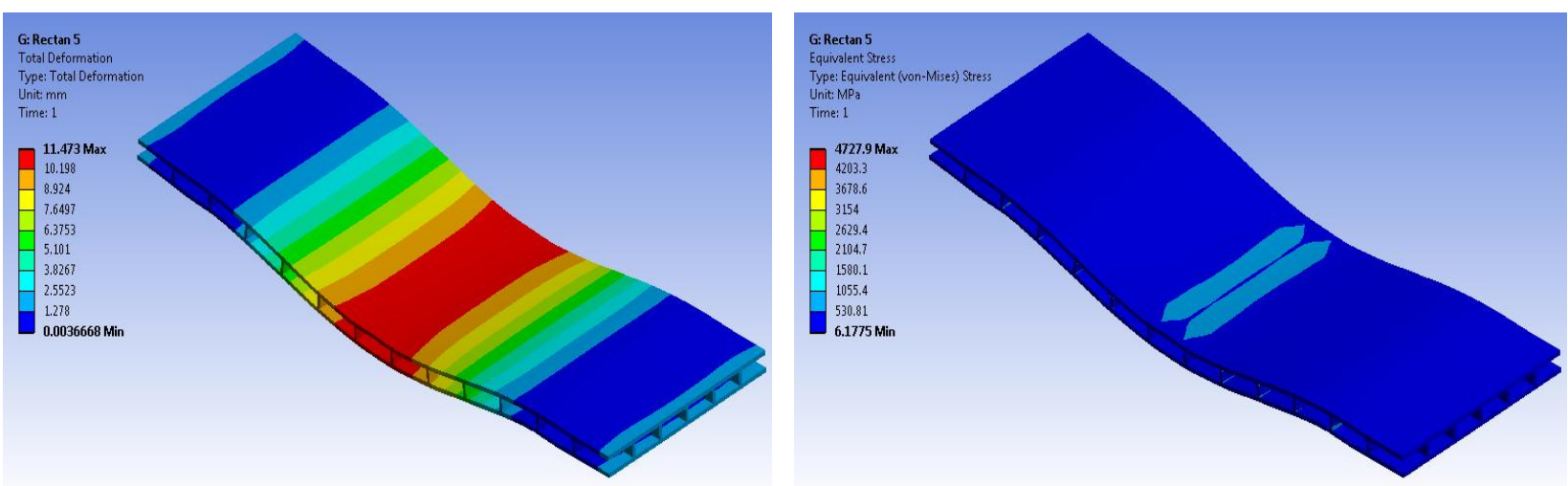

Fig. (13) Deformation and stress of structure with five stiffeners in longitudinal direction and twelve stiffeners in transverse direction.
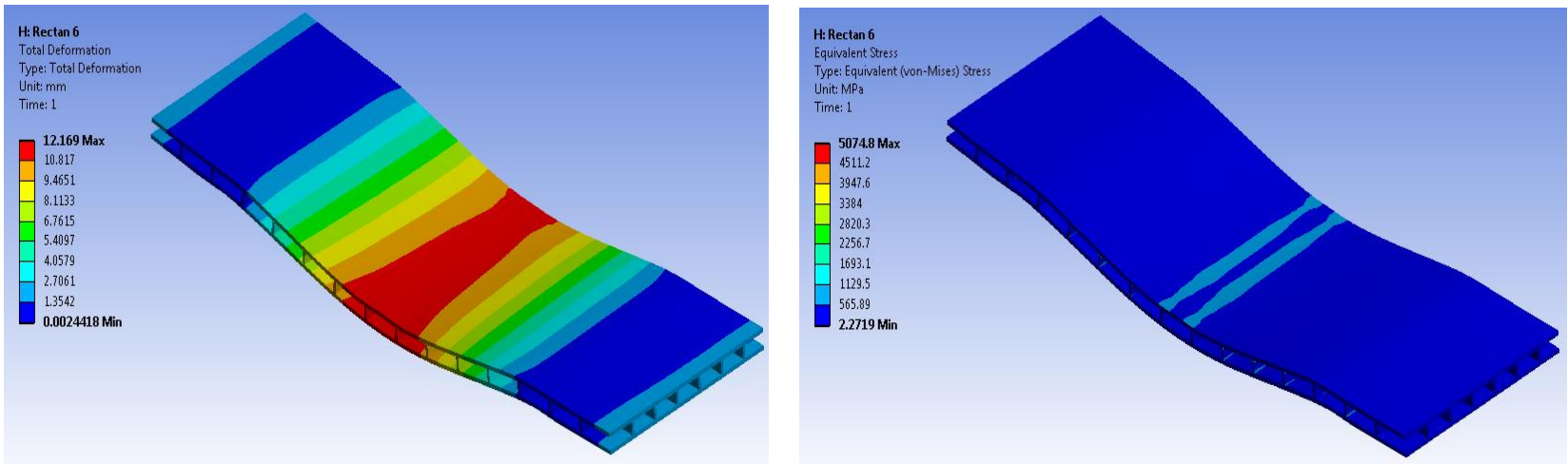

Fig. (14) Deformation and stress of structure with six stiffeners in longitudinal direction and fourteen stiffeners in transverse direction.

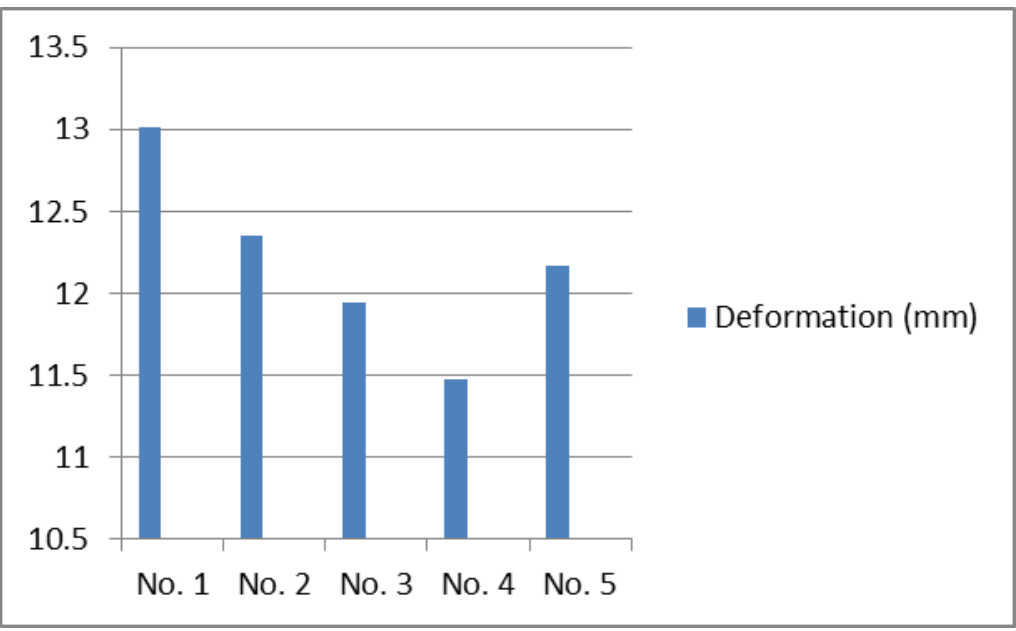

Fig. (15) Structure deformation for different number of stiffeners. 


\section{REFERENCES}

George S. Springer, 2003, "Mechanics of Composite Structures”, Cambridge University Press.

Jabihulla Shariff Md and Sudhir Chakravarthy, 2016, "Comparison of Tensile Strength with Experimental and Numerical Analysis of a Sandwich Panel of Rhombus and Hexagonal Honeycomb Core Structures", International Journal of Engineering Science and Computing, Vol. 6, No. 6, p.p. 7048-7053.

Jeom Kee Paik, Anil K. Thayamballi and Gyu Sung Kim, 1999, "The strength characteristics of aluminum honeycomb sandwich panels", journal of Thin-Walled Structures, Vol. 35, p.p. 205231.

Kiumars Farhadi, Amir Afkar and Majid Nouri Kamari, 2015, "Numerical simulation of metallic honeycomb sandwich panel structures under dynamic loads", Journal of Materials and Environmental Science, Vol. 6, No. 7, p.p. 2013-2020.

Mamalis, A.G., Manolakos, D.E., Ioannidis, M.B. and D.P. Papapostolou, 2005, "On the crushing response of composite sandwich panels subjected to edgewise compression: experimental", Composite Structures Journal, Vol. 71, p.p. 246-257.

Nguyen, M.Q., Jacombs, S.S., Thomson, R.S., Hachenberg, D. and M.L. Scott, 2005, "Simulation of impact on sandwich structures", Composite Structures Journal, Vol. 67, p.p. 217-227.

Nitin Ratan Gir, A.Z Patel and A.B Ghalke, 2016, "FEA and Experimental analysis of Honeycomb sandwich panel using glass fiber", International Journal of Mechanical Engineering, Vol. 4, Issue 10, p.p. 16-23.

Sakhi Jan, Rafi Ullah khan, Sajjad Ahmad, Muhammad Amjad, Saeed Badshah and Mutahir Ahmad, 2015, "Flexural strength of honey comb sandwich structures", International Journal of Applied Sciences and Engineering Research, Vol. 4, No. 1, p.p. 86-93.

Satay Pal Singh Arora and Nirmala Rachel James, 2016, " Study the Effect of Core Design on Mechanical Behaviour of Honeycomb Sandwich Structures under Three Point Bending", International Journal of Innovative Research in Science, Engineering and Technology, Vol. 5, Issue 6, p.p. 9444-9449.

Sezgin, M. Tanog Lu, Egilmez and C. Donmez, 2010, "Mechanical Behavior of Polypropylenebased Honeycomb-Core Composite Sandwich Structures", Journal of Reinforced Plastics and Composites, Vol. 29, No. 10, p.p. 1569-1597.

Rocca S.V. and Nanni A., 2005, "Mechanical characterization of sandwich structure comprised of glass fiber reinforced core: Part 1", Third International Conference-Composites in Construction, Lyon, France, July 11 - 13, 2005, Missouri University of Science and Technology. http://utc.mst.edu/ (accessed June 25, 2007).

Zakeri A.A. and Talebi Mazraehshahi H., 2010, "Experimental study on mechanical properties of aircraft honeycomb sandwich structures", 14th International Conference on Experimental Mechanics, France, 4-9 July. 